\title{
Analisis Ketepatan Pengukur Daya dan Faktor Daya Listrik Berbasis Arduino Uno R3 328P
}

\author{
Wilda Noer Agustianingsih, Freddy Kurniawan*, Paulus Setiawan. \\ Departemen Teknik Elektro, Sekolah Tinggi Teknologi Adisutjipto, Yogyakarta \\ *email: freddykurniawan@stta.ac.id
}

\begin{abstract}
Electric power and power factor are two parameters that must be considered because they involve the quality of the energy consumed. In order to be able to analyze these, a microcontroller-based power and power factor meter are needed which can be further developed. In this research, a power and power factor meter based on the ATmega328P microcontroller was developed on the Arduino board. Several algorithms are used to calculate the frequency of the grids, as well as the true-RMS of voltage and current. From the instantaneous values of the voltage and current, the power and power factor can be calculated. The simulation results show that this system can measure the power and power factor for input voltages of 100 to 300 volts with a frequency of 45 to $156 \mathrm{~Hz}$ for loads up to 5 amperes. The mean calculation average error for linear load is $0.28 \%$ for active power and $-0.33 \%$ for apparent power. Meanwhile, for nonlinear loads, the calculation average error for active power is $1.86 \%$ and apparent power is $0.47 \%$.
\end{abstract}

Keywords — power meter, power factor meter, microcontroller ATmega 328P, arduino.

\section{Pendahuluan}

Daya listrik adalah laju energi listrik yang terjadi pada suatu rangkaian listrik. Perubahan arus dan tegangan yang terjadi pada masukan daya dapat mempengaruhi besarnya nilai daya listrik yang dikeluarkan. Tidak semua daya yang dihasilkan dapat dimanfaatkan sebagai daya aktif. Terdapat juga daya reaktif yang merupakan bagian yang tidak memberikan manfaat secara langsung. Rasio besarnya daya yang bisa digunakan terhadap daya tampak yang dihasilkan sumber inilah yang disebut sebagai faktor daya [1]. Faktor daya merupakan besaran yang menunjukkan seberapa efisien jaringan yang dimiliki dalam menyalurkan daya yang bisa dimanfaatkan. Semakin tinggi faktor daya mendekati berarti semakin banyak daya yang bisa dimanfaatkan. Besarnya nilai daya dan faktor daya harus dimonitor dengan baik karena akan berpengaruh terhadap biaya tagihan listrik.

Penelitian ini merupakan pengembangan dari penelitian sebelumnya oleh Nanda F. W., (2020) dengan judul "Analisis Ketepatan Pengukur Tegangan True-RMS Jala-jala Listrik Berbasis Mikrokontroler ATmega 328P” [2]. Penelitian tersebut menggunakan mikrokontroler ATmega 328P sebagai komponen utama untuk mencuplik (sampling) nilai tegangan dan menghitung nilai tegangan true-RMS. Hasil pengujian menunjukkan bahwa sistem ini memiliki ketepatan pengukuran tegangan yang baik dengan galat rata-rata untuk pengukuran tegangan true-RMS listrik jala-jala adalah 0,21\%, dengan kesibukan CPU mikrokontroler ratarata adalah $13 \%$.

Selanjutnya dari penelitian Rustianik, Y., (2020) dengan judul "Analisis Ketepatan Pengukur Arus RMS Beban Listrik Berbasis Mikrokontroler ATmega 328P" [3]. Pada penelitian tersebut data tegangan dan arus dicuplik masing-masing 128 kali frekuensi masukan. Sistem tersebut dapat bekerja dengan ketepatan pengukuran yang baik, memiliki nilai galat rata-rata pengujian beban linear $0,49 \%$ dan galat arus beban nonlinear adalah $0,41 \%$. Kesibukan CPU untuk pengujian dengan masukan frekuensi terendah adalah 4,75\% dan untuk masukan frekuensi tertinggi adalah $21,2 \%$. 
Penelitian tersebut selanjutnya dikembangkan oleh Fauziah N., (2020) dengan judul “Analisis Ketepatan Pengukur Frekuensi Listrik Berbasis Mikrokontroler ATmega 328P". Pada penelitian ini tegangan masukan diumpankan ke rangkaian schmitt trigger untuk diubah karakteristiknya ke bentuk square. Keluaran schmitt trigger dimasukkan ke pin external interupt mikrokontroler untuk pembacaan periode gelombang tegangan masukkan. Pembacaan periode gelombang dilakukan sebanyak 16 kali periode isyarat masukan agar pembacaannya lebih akurat. Hasil pengujian menunjukkan bahwa sistem dapat mengukur frekuensi tegangan jala-jalan dengan tepat pada masukkan frekuensi $5 \mathrm{~Hz}$ hingga $200 \mathrm{~Hz}$ [4].

Penelitian ini merupakan pengembangan dari penelitian [2-4] dengan optimalisasi dan efisiensi program mikrokontroler untuk penghematan memori mikrokontroler. Penelitian ini menggunakan mikrokontoler ATmega 328P sebagai komponen utamanya. Mikrokontroler jenis ini memiliki memori yang bisa ditingkatkan (expandable) [5] sehingga dapat dikembangkan untuk dibuat data logger ke komputer atau android.

\section{Tinjauan Pustaka}

\subsection{Daya Listrik}

Terdapat tiga daya pada suatu sistem tegangan bolak-balik (AC) yaitu daya aktif (P) dengan satuan watt (W), daya reaktif (Q) dengan satuan volt ampere reaktif (VAR) dan daya semu (S) dengan satuan volt ampere (VA) [6]. Daya aktif adalah besar nilai suatu daya ratarata yang sesuai dengan kekuatan tenaga yang dikonsumsi oleh beban. Sementara itu, daya semu adalah besar nilai suatu daya yang dihasilkan dari perkalian antara nilai rata-rata efektif dari tegangan listrik sumber dan arus listrik yang mengalir ke beban. Daya semu merupakan daya yang dikeluarkan dari sumber listrik atau yang diserap oleh beban. Sementara itu, daya reaktif adalah besar nilai dari daya yang diperlukan untuk pembentukan medan magnet. Dari pembentukan suatu medan magnet itu maka akan terbentuk fluks medan magnet untuk mendukung suatu fungsi, misalnya menggerakkan motor.

\subsection{Faktor Daya}

Faktor daya menggambarkan sudut phasa antara daya aktif dan daya semu yang terdapat pada segitiga daya. Faktor daya juga merupakan besar nilai yang didapati dari hasil perbandingan antara nilai daya aktif dengan nilai daya semu yang ada dalam sebuah rangkaian listrik.

Pada suatu sistem tenaga listrik memiliki 3 jenis faktor daya yaitu [7]:

1. Faktor daya bernilai satu (unity): keadaan saat nilai $\operatorname{Cos} \theta$ adalah bernilai satu dan tegangan sumber sephasa dengan arus ke beban. Faktor daya unity akan terjadi bila jenis beban adalah resistif murni.

2. Faktor daya mendahului (leading): keadaan faktor daya saat memiliki kondisi beban listrik yang beban bersifat kapasitif.

3. Faktor daya terbelakang (lagging): keadaan faktor daya saat memiliki kondisi beban atau peralatan listrik memerlukan daya reaktif dari sistem atau beban bersifat induktif.

Sementara itu, beban listrik terdiri dari dua jenis yaitu beban linear dan beban nonlinear. Suatu beban disebut linear bila arusnya berbanding lurus terhadap tegangan sehingga bentuk gelombang arus yang mengalir ke beban akan sama dengan bentuk gelombang tegangan dari sumber. Sedangkan untuk beban nonlinear, bentuk gelombang arus tidak sama dengan bentuk gelombang tegangan. 


\section{Metodologi Penelitian}

\subsection{Rangkaian Elektronis Sistem}

Model rangkaian disimulasikan dalam perangkat lunak Proteus. Di sini digunakanlah ATmega 328P dalam papan Arduino Uno sebagai penghitung nilai daya dan faktor daya. Sistem simulasi dirancang untuk mendapat masukan berupa tegangan 100 volt hingga 300 volt dengan rentang frekuensi $45 \mathrm{~Hz}$ hingga $156 \mathrm{~Hz}$. Beban yang digunakan menarik arus 0 hingga 5 ampere. Blok diagram sistem dapat dilihat pada Gambar 1.

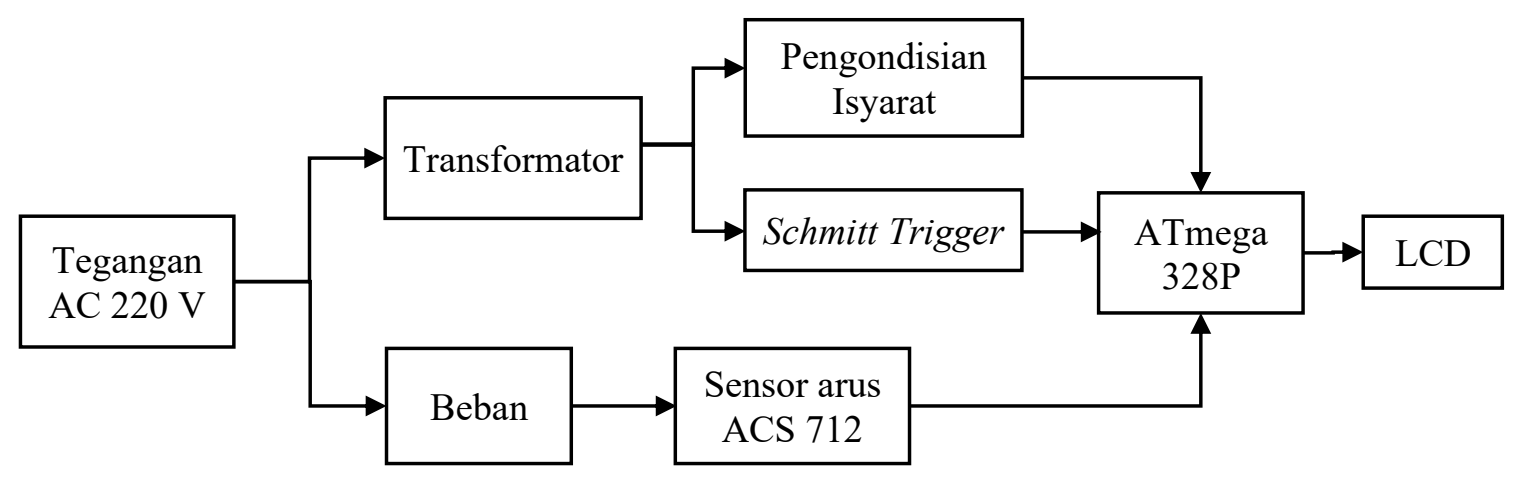

Gambar 1. Blok diagram sistem

Rangkaian elektronis sistem terdiri dari beberapa komponen utama yaitu: transformator step down, rangkaian Schmitt Trigger, pengkondisi isyarat, sensor arus ACS712, rangkaian mikrokontroler ATmega328P dan rangkaian LCD. Skema rangkaian ini dapat dilihat pada Gambar 2 dan Gambar 3.

Transformator step down berfungsi untuk menurunkan nilai tegangan sumber sebelum diumpankan ke rangkaian pengkondisi isyarat. Masukan yang diterima transformator adalah 100 volt hingga 300 volt. Transformator diatur untuk bekerja dengan transform ratio 20 sehingga nilai keluaran transformator adalah $\frac{1}{20}$ tegangan masukan. Masukan tegangan dari jala-jala listrik PLN diumpankan ke lilitan primer transformator sehingga didapat beberapa tegangan di lilitan sekundernya.

Salah satu keluaran dari transformator dimasukkan ke rangkaian yang terdiri dari resistor R1 dan Schmitt trigger dalam IC 74HC14. Rangkaian tersebut berfungsi untuk mengubah isyarat sinusoida keluaran transformator menjadi gelombang kotak. Isyarat gelombang kotak ini dimasukkan ke masukan INT0 (interrupt 0 ) yaitu pin IO2 mikrokontroler. Dengan mengembangkan algoritma yang telah dibuat di Referensi [4] dan [8], dan dengan menentukan jeda waktu isyarat sisi naik gelombang kotak, dapatlah ditentukan nilai periode dan frekuensi gelombang tegangan masukan.

Keluaran lain transformator dihubungkan ke sebuah pengkondisi isyarat. Rangkaian yang dibentuk oleh R2, R3, R4 dan C1 ini diperlukan untuk penambahan nilai offset 2,5 volt. Penambahan ini diperlukan karena ADC tidak dapat menerima tegangan di bawah 0 volt (minus). Kemudian keluaran dari pengkondisi isyarat diumpankan ke masukan ADC 0 yaitu pin AD0 dari mikrokontroler ATmega328P. Mikrokontroler mencuplik tegangan di pin ini untuk dikonversi menjadi data digital yang mewakili tegangan sesaat masukan.

Masukan arus dilewatkan ke sensor arus ACS 712 05B sehingga didapat tegangan keluaran yang mewakili nilai arus. Selanjutnya tegangan tersebut diumpankan ke masukan ADC 1 yaitu pin AD1 mikrokontroler. Mikrokontroler mencuplik tegangan di pin ini untuk dikonversi menjadi data digital yang mewakili nilai arus sesaat di beban. 


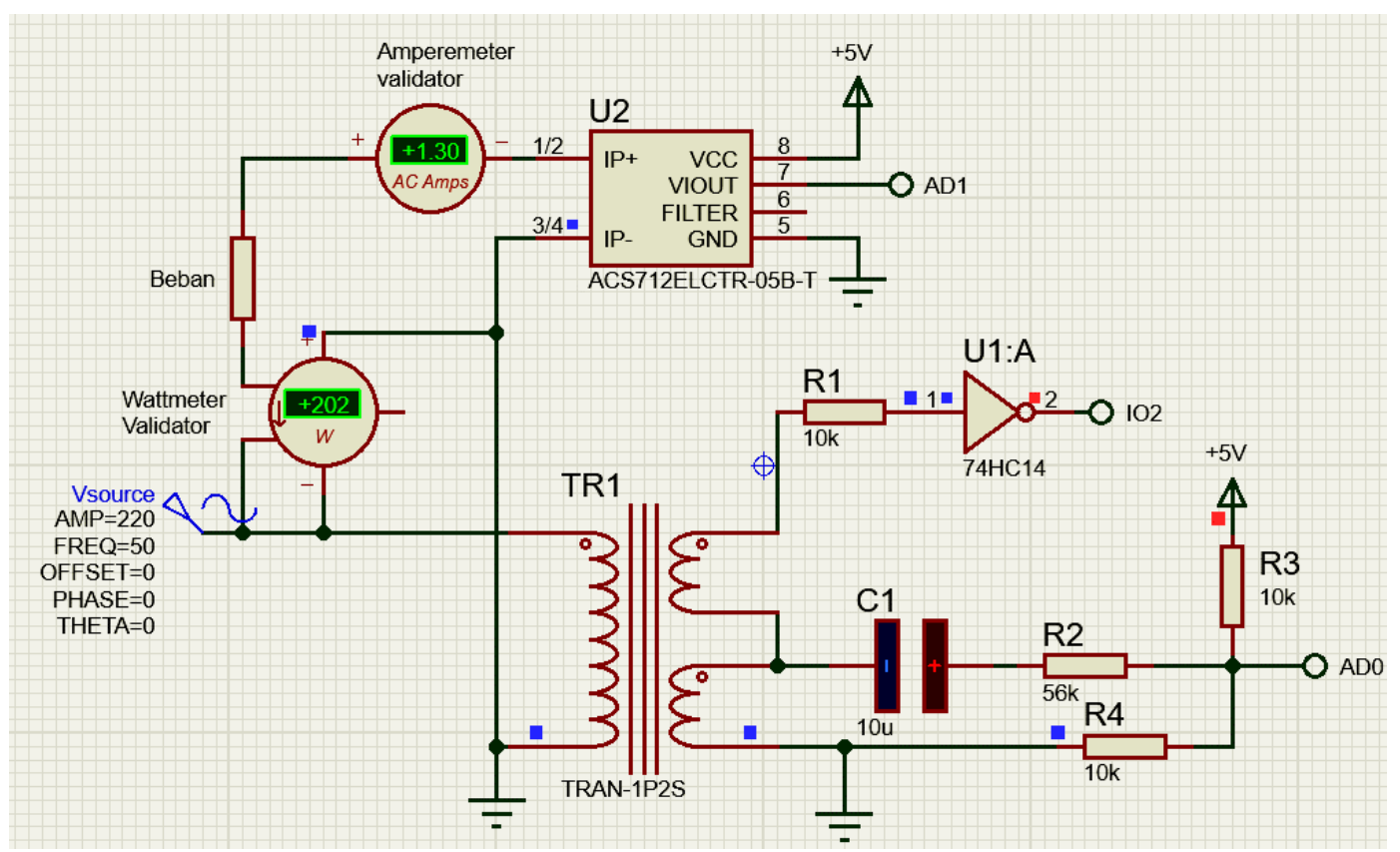

Gambar 2. Skema rangkaian pengujian untuk beban nonlinear
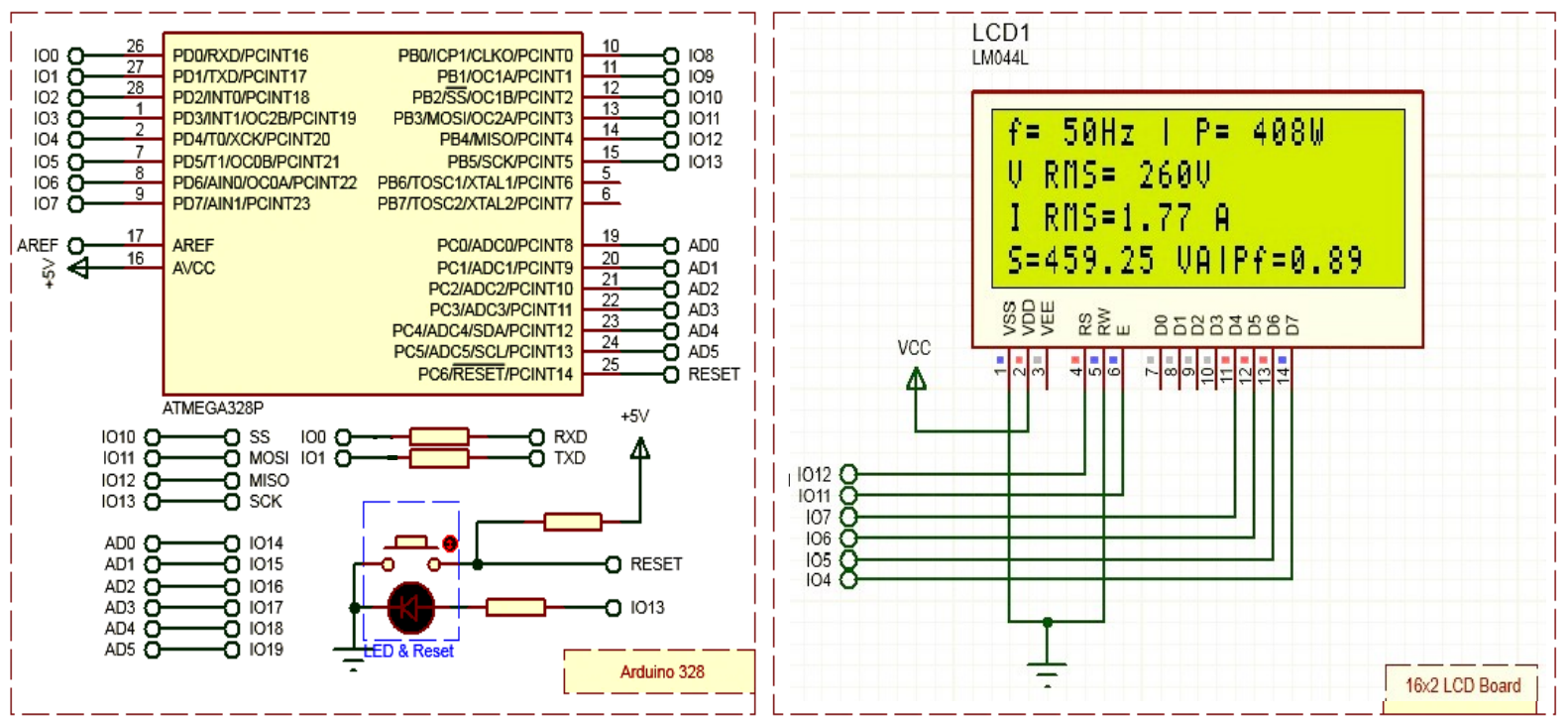

Gambar 3. Rangkaian mikrokontroler ATmega 328P dan LCD

Mikrokontroler yang digunakan pada penelitian ini adalah ATmega 328P. Mikrokontroler ini dikemas dalam papan Arduino Uno R3. Proses pengukuran frekuensi, pencuplikan data, penghitungan nilai tegangan dan arus RMS, penghitungan daya dan faktor daya dikerjakan oleh mikrokontroler ATmega 328P ini dan diatur dengan suatu penjadwalan. Nilai frekuensi, tegangan dan arus true-RMS, daya dan faktor daya hasil hitungan mikrokontroler ditampilkan pada sebuah LCD. Skema rangkaian elektronis mikrokontroler dengan LCD dapat dilihat pada Gambar 3.

Pengujian sistem dilakukan dengan membandingkan nilai daya yang ditampilkan LCD dengan data nilai terlihat di wattmeter validator. Mode wattmeter pada simulasi proteus ini dapat diubah untuk pengukuran daya aktif maupun daya semu. 


\subsection{Penjadwalan Proses di Mikrokontroler}

Untuk dapat menghitung nilai daya dan faktor daya, terdapat beberapa proses utama yang terlebih dahulu harus dilakukan oleh mikrokontroler, yaitu: menghitung frekuensi tegangan masukan, menghitung true-RMS tegangan masukan dan menghitung true-RMS arus yang mengalir ke beban. Setiap proses dilakukan oleh sebuah sub rutin. Sebagaimana proses penghitungan nilai tegangan true-RMS pada penelitian sebelumnya [2-4], eksekusi setiap sub rutin dikerjakan berdasarkan pewaktuan yang dibentuk oleh siklus gelombang tegangan masukan. Satu siklus berlangsung selama satu periode gelombang tegangan masukan.

Proses pencuplikan data di ADC 0 dan ADC 1 terjadi pada siklus ke-17. Data dicuplik sebanyak 64 kali dalam satu periode gelombang. Data yang telah dicuplik disimpan di memori mikrokontroler. Selanjutnya dilakukan proses perhitungan nilai tegangan dan arus RMS menggunakan algoritma yang dikembangkan dari Referensi [2-3] dan [9], baru kemudian dihitung nilai daya dan faktor daya. Pewaktuan setiap sub rutin yang dikerjakan mikrokontroler dapat dilihat pada diagram alir sistem sebagaimana Gambar 4.

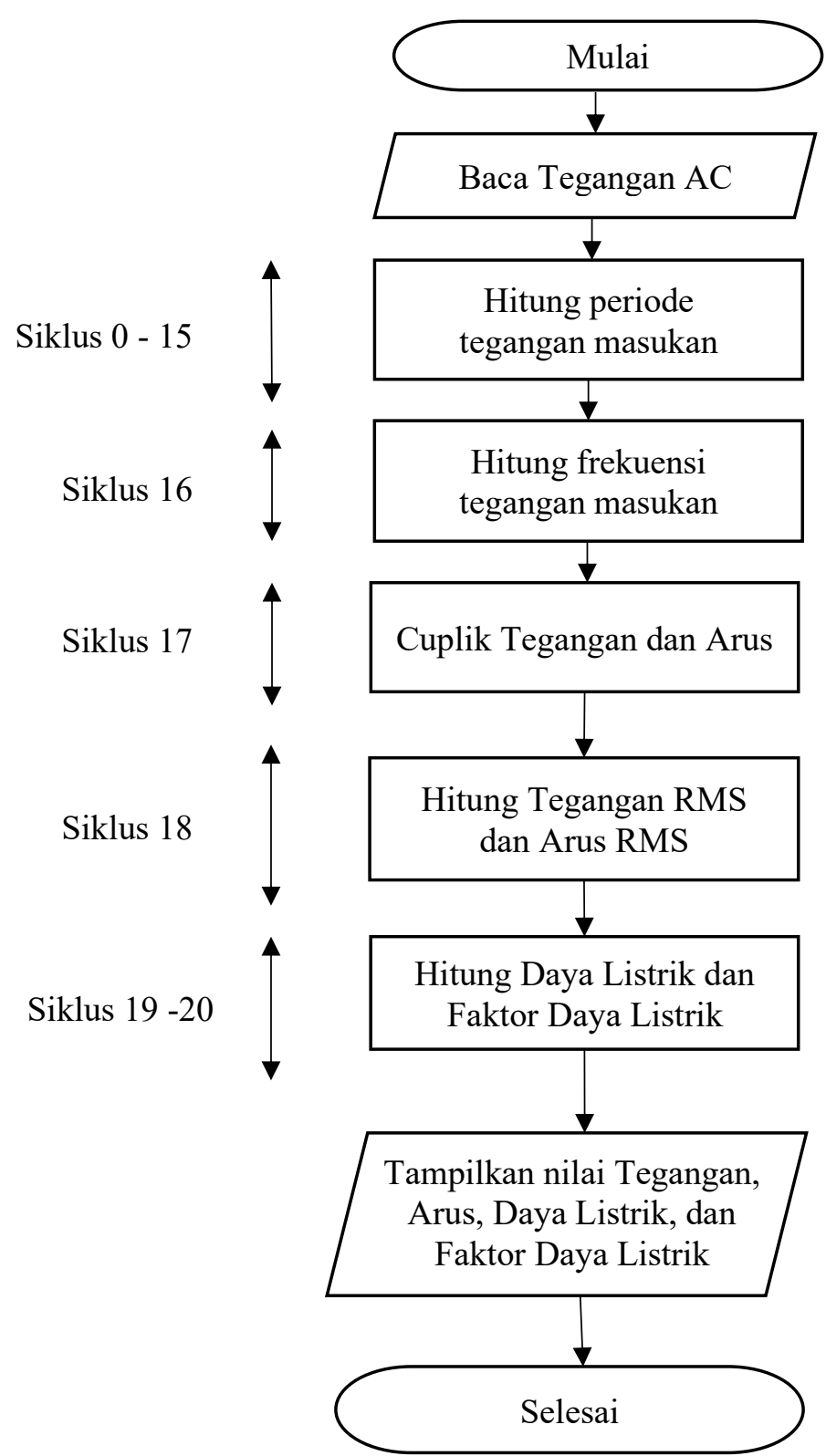

Gambar 4. Diagram Alir Sistem 


\subsection{Pengolahan Data Menggunakan Mikrokontroler}

Pengolahan data pada mikrokontroler dibagi menjadi empat sub bagian yaitu:

a. Penghitungan Frekuensi Tegangan

Frekuensi merupakan jumlah periode gelombang listrik yang terjadi tiap detik. Nilai frekuensi mempengaruhi durasi proses pencuplikan data pada satu gelombang. Penghitungan frekuensi itu sangatlah penting karena pada dasarnya pencuplikan data itu dapat berubah-ubah mengikuti frekuensi masukannya. Pada penelitian ini digunakan Schmit triger sebagai pengubah bentuk gelombang masukan ke bentuk pulsa. Keluaran Schmitt triger diumpankan ke pin external interrupt mikrokontroler untuk pembacaan nilai periode. Timer ATmega 328P telah diatur untuk mengukur jeda waktu selama 16 periode gelombang tegangan masukan [4]. Dari 16 periode gelombang tersebut, dapat ditentukan nilai frekuensi gelombang tegangan masukan.

\section{b. Konversi Masukan ke Bentuk Digital}

Tegangan keluaran dari pengkondisi isyarat adalah isyarat analog dengan nilai amplitudo maksimal 1,7 volt dan offset 2,5 volt. ADC mikrokontroler ATmega 328P merupakan konverter nilai tegangan analog ke data digital 10 bit, artinya bahwa ada $2^{10}=1024$ nilai berbeda yang dapat dihasilkan dari ADC. Adapun rumus untuk menentukan nilai data keluaran ADC mengikuti Persamaan (1) berikut [10].

$$
\text { Data } \mathrm{ADC}=\frac{\left(\mathrm{v}_{\text {in }} \times 2^{n}\right)}{\mathrm{v}_{\mathrm{ref}}}
$$

$\mathrm{v}_{\text {in }}$ merupakan isyarat masukan, $n$ merupakan bit resolusi konverter ADC ATmega yaitu 10 bit, dan $\mathrm{v}_{\text {ref }}$ merupakan tegangan referensi (menggunakan 5 volt). Adapun resolusi dan ketelitian ADC dapat dihitung menggunakan Persamaan (2) berikut.

$$
k=\frac{v_{\text {ref }}}{2^{n}-1}
$$

$k$ merupakan resolusi pengonversian ADC. Dengan $\mathrm{v}_{\text {ref }}=5$ volt dan $n=10$ bit akan didapat resolusi konversi 4,9 milivolt. Nilai ini menjadi nilai kesalahan terbesar ADC akibat konversi dari nilai analog ke digital.

\section{c. Pencuplikan Isyarat Tegangan}

Frekuensi pencuplikan isyarat minimal adalah dua kali frekuensi masukan [11]. Sistem ini mencuplik dua isyarat masukan yaitu isyarat tegangan dan isyarat arus dengan berselangan (interlacing). Agar penghitungan tegangan menjadi presisi, maka isyarat tegangan dan arus dicuplik dengan frekuensi cuplikan 64 kali dari frekuensi masukannya. Nilai frekuensi cuplikan akan berubah dengan berubahnya frekuensi tegangan masukan.

Secara teori, ADC membutuhkan waktu 30 mikrodetik untuk proses konversi tegangan atau arus. Prosesor di mikrokontroler membutuhkan waktu tambahan hingga 20 mikrodetik [2] lagi agar konversi di ADC tersebut dapat berjalan dengan baik. Durasi waktu tersebut di antaranya digunakan untuk: memanggil sub rutin interupsi (ISR), menyimpan data keluaran ADC ke memori, dan kembali ke rutin utama (return interrupt, RETI). Sehingga waktu total yang dibutuhkan adalah 50 mikrodetik. Dengan demikian, dengan jumlah cuplikan $64 \times 2=$ 128 kali, maka frekuensi maksimal yang dapat dihitung mengikuti Persamaan (3).

$$
\begin{aligned}
f_{\text {maks }} & =\frac{1}{50 \mu \times(64 \times 2)} \\
& =156,25 \mathrm{~Hz}
\end{aligned}
$$


Proses pencuplikan isyarat tegangan dan arus untuk frekuensi tegangan masukan $50 \mathrm{~Hz}$ dapat dilihat pada Gambar 5. Dari proses pencuplikan ini akan diperoleh data cuplikan yang mewakili grafik tegangan masukan dan arus yang melewati beban. Data tersebut tersimpan di memori mikrokontroler.

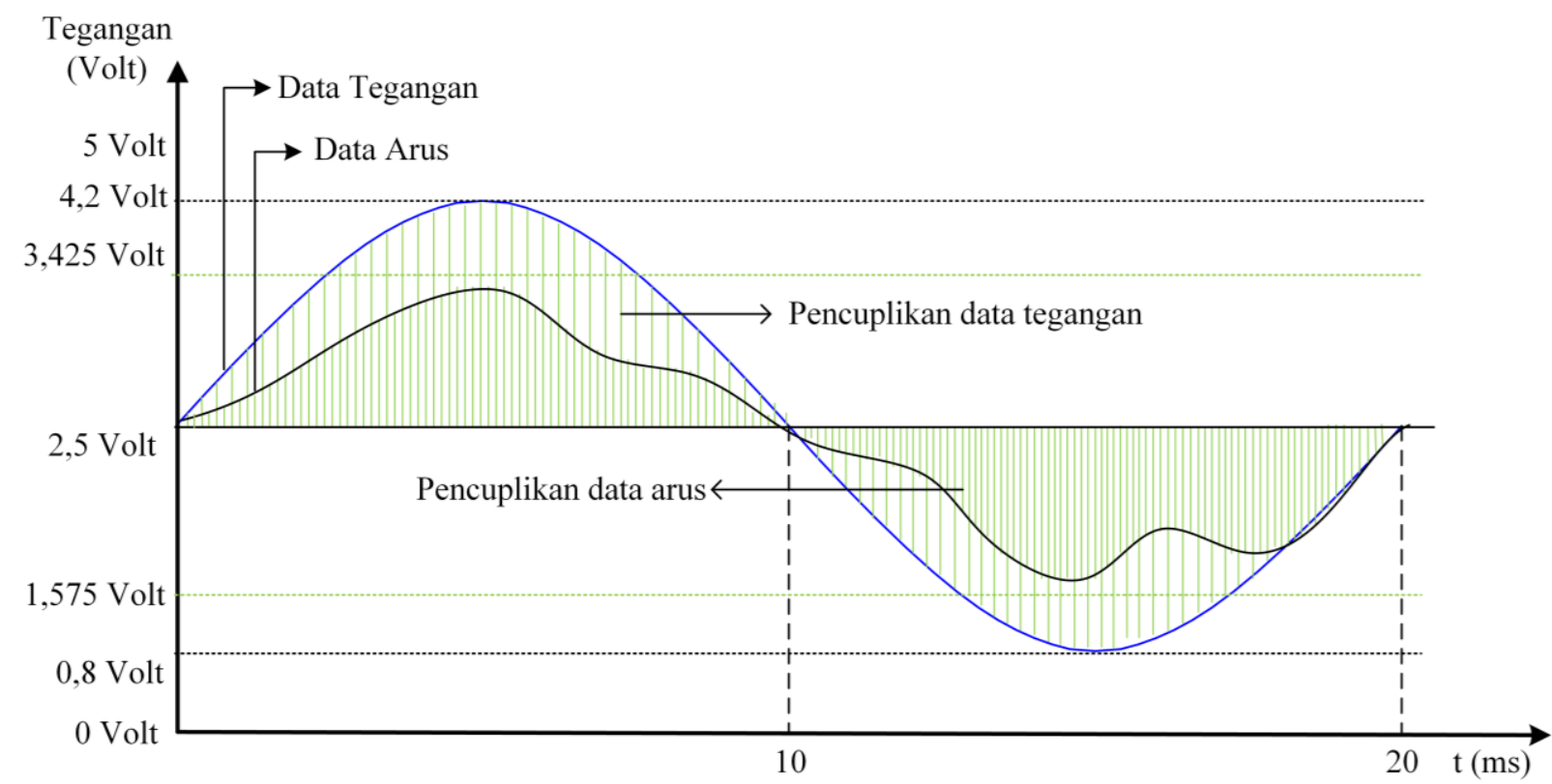

Gambar 5. Pencuplikan tegangan dan arus

d. Perhitungan Daya dan Faktor Daya

Dari data hasil cuplikan isyarat tegangan dan arus yang telah disimpan di dalam memori mikrokontroler, dapat dihitung nilai daya menggunakan persamaan dalam bentuk diskret berikut.

$$
\mathrm{P}=\frac{1}{\mathrm{~N}} \sum_{\mathrm{N}-0}^{\mathrm{N}-1} v_{n} X i_{n}
$$

$\mathrm{P}$ merupakan daya, $\mathrm{N}$ merupakan banyaknya cuplikan per periode, $v_{n}$ merupakan data tegangan cuplikan ke- $n$, dan $i_{n}$ merupakan data arus cuplikan ke- $n$. Dari hasil perhitungan nilai daya yang didapati, dapat dihitung besar faktor daya $p f$ menggunakan Persamaan (5) [1].

$$
p f=\frac{P}{V_{r m s} \times I_{r m s}}
$$

$V_{r m s}$ merupakan nilai true-RMS dari tegangan masukan dan $I_{r m s}$ merupakan nilai true-RMS dari arus ke beban.

\subsection{Monitor Sistem}

Monitoring sistem diperlukan untuk memantau kinerja dari sistem tersebut. Sistem perhitungan daya listrik dan faktor daya listrik dapat dipantau secara realtime pada layar osiloskop. Pemantauan sistem secara real time dilakukan dengan pada IO13 pada mikrokontroler. IO13 berlogika tinggi (high) ketika prosesor mikrokontroler mengeksekusi perintah dan berlogika rendah (low) ketika tidak sedang mengeksekusi perintah (idle). Dengan cara ini sistem dapat dipantau kapan waktu sibuk dan kapan waktu idle-nya. Dengan menganalisis waktu idle, sistem nantinya masih dapat dikembangkan dengan menambahkan 
algoritma lain yang dieksekusi pada saat prosesor mikrokontroler dalam keadaan idle. Secara lebih detail, monitoring sistem dapat dilihat pada Referensi [2].

\section{Hasil Dan Analisa}

\subsection{Proses Pencuplikan Tegangan dan Arus}

Sistem ini mencuplik dua isyarat masukan yaitu isyarat tegangan dan isyarat arus. Isyarat tegangan yang telah ditambah offset 2,5 volt diumpankan ke pin ADC 0 , sementara itu untuk isyarat tegangan yang mewakili arus sebagai keluaran sensor arus ACS712 05B diumpankan ke pin ADC 1. Mikrokontroler ATmega 328P bekerja pada frekuensi $8 \mathrm{MHz}$. Dengan prescaler $=8$, ADC diatur untuk bekerja pada frekuensi $f_{A D C}=1 \mathrm{MHz}$. Frekuensi kerja ADC dapat dihitung dengan menggunakan Persamaan 8 [9].

$$
\begin{aligned}
f_{A D C} & =\frac{f_{C P U}}{\text { prescaler }} \\
& =\frac{8 \mathrm{MHz}}{8}=1 \mathrm{MHz}
\end{aligned}
$$

$f_{A D C}$ merupakan frekuensi kerja ADC, $f_{C P U}$ merupakan frekuensi kerja CPU, dan prescaler merupakan pembagi frekuensi yang digunakan. ADC diatur untuk bekerja pada frekuensi $1 \mathrm{MHz}$. Dengan frekuensi kerja $1 \mathrm{MHz}$, maka waktu satu siklus ADC dapat dihitung menggunakan Persamaan 7 [10].

$$
\begin{aligned}
T_{A D C} & =\frac{1}{f_{A D C}} \\
& =\frac{1}{1 \mathrm{MHz}}=1 \text { mikrodetik }
\end{aligned}
$$

$T_{A D C}$ merupakan periode siklus ADC dan $f_{A D C}$ merupakan frekuensi kerja ADC.

Sebagaimana Referensi [5], ADC mikrokontroler ini membutuhkan waktu untuk sample \& hold sebesar 1,5 periode clock ADC dan untuk pencuplikan dan konversi membutuhkan waktu 13,5 periode clock ADC. Sehingga total waktu yang dibutuhkan untuk satu kali pencuplikan adalah 15 siklus.

Dengan periode satu siklus ADC sebesar 1 mikrodetik, maka waktu yang dibutuhkan mikrokontroler untuk dua kali pencuplikan adalah $2 \times 15=30$ mikrodetik. Waktu yang tersedia untuk 1 kali pencuplikan berubah mengikuti frekuensi masukan. Apabila frekuensi masukan sistem adalah $50 \mathrm{~Hz}$, maka waktu yang tersedia untuk 1 kali pencuplikan dapat dihitung menggunakan Persamaan (8) [2].

$$
\begin{aligned}
t & =\frac{1}{f_{\text {in }} \times n} \\
& =\frac{1}{50 \mathrm{~Hz} \times 128}=156,25 \text { mikrodetik }
\end{aligned}
$$

$t$ merupakan waktu yang tersedia untuk pencuplikan, $f_{\text {in }}$ merupakan frekuensi masukan, dan $n$ merupakan jumlah cuplikan.

ADC membutuhkan waktu 30 mikrodetik untuk pencuplikan tegangan dan arus. Sementara itu, mikrokontroler membutuhkan waktu tambahan 20 mikrodetik untuk menyimpan data hasil cuplikan ke memori, penambahan (increase) nilai variabel $i$ untuk pengulangan pencuplikan dan pemanggilan sub rutin pencuplikan. Sehingga waktu total yang dibutuhkan adalah 50 mikrodetik. Dengan jumlah cuplikan 64 kali masing-masingnya, maka 
frekuensi maksimal yang dapat diukur, dihitung menggunakan Persamaan (9) [2].

$$
\begin{aligned}
f_{\text {max }} & =\frac{1}{\left(2 T_{S}+\left(2 \times T_{\text {OTH }}\right) \times n\right.} \\
& =\frac{1}{50 \mu \times(2 \times 64)}=156,25 \mathrm{~Hz}
\end{aligned}
$$

Sebagaimana Persamaan (9), $f_{\max }$ merupakan frekuensi maksimal yang dapat diukur, $T_{S}$ merupakan waktu yang tersedia untuk pencuplikan, dan $T_{\text {OTH }}$ merupakan waktu untuk mengerjakan proses pendukung, misalnya pemanggilan interupsi dan kembali ke rutin sebelumnya.

Pencuplikan tegangan dan arus pada frekuensi $50 \mathrm{~Hz}$, dapat dikerjakan dengan baik oleh ADC mikrokontroler dimana pencuplikan arus dan tegangan dilakukan sebanyak 64 kali masing-masingnya dalam 1 periode penuh. Data nilai sesaat tegangan dan arus dalam satu periode tersebut tersimpan di memori mikrokontroler dan dapat dibuat grafik sebagaimana Gambar 10. Kurva berwarna hijau merupakan grafik data cuplikan yang mewakili tegangan keluaran rangkaian pengondisi isyarat. Grafik inilah yang diumpankan ke pin AD0 mikrokontroler ATmega328P. Grafik tegangan tersebut mewakili tegangan masukan. Sedangkan kurva merah merupakan grafik data cuplikan yang mewakili tegangan keluaran sensor arus. Grafik inilah yang diumpankan ke pin AD1 mikrokontroler. Grafik tegangan tersebut mewakili arus yang melewati beban. Jika diperlukan, grafik ini nantinya dapat ditampilkan di LCD dot matrix atau dikirim ke komputer.

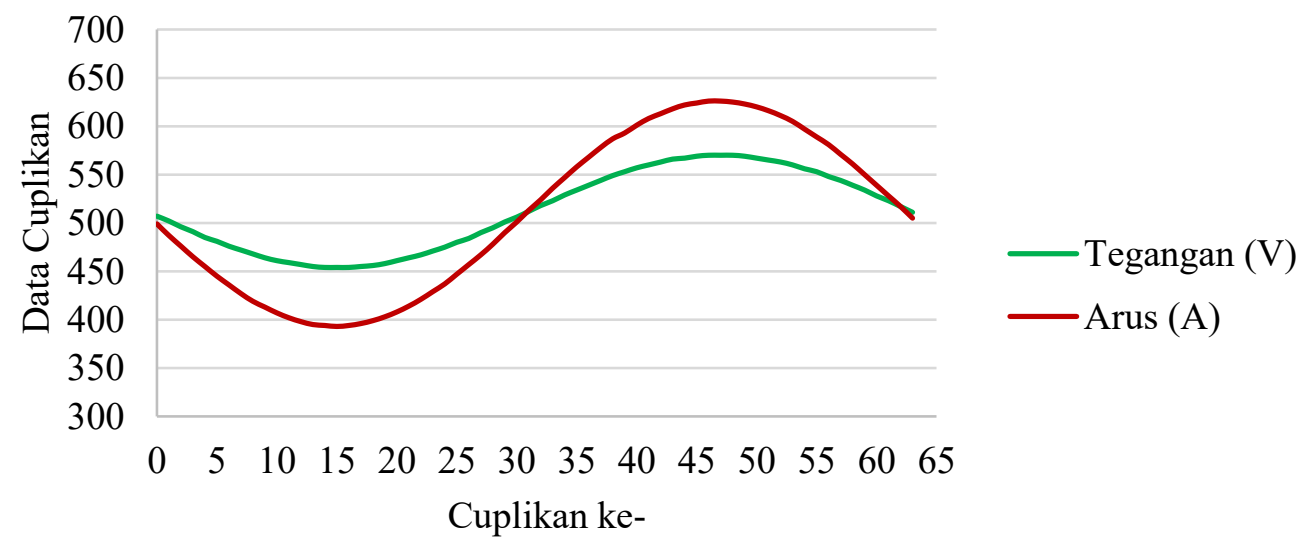

Gambar 10. Grafik data hasil pencuplikan tegangan dan arus berfrekuensi $50 \mathrm{~Hz}$

\subsection{Hasil Pengujian Beban Linear}

Simulasi ini diuji menggunakan wattmeter yang ada pada simulasi proteus sebagai validator. Sistem ini dirancang untuk menghitung daya dan faktor daya untuk tegangan masukan yang bervariasi mulai dari 100 volt hingga 300 volt dengan frekuensi tegangan dari $45 \mathrm{~Hz}$ hingga $156 \mathrm{~Hz}$ dengan rentang arus beban 0 A hingga $5 \mathrm{~A}$. Data uji didapatkan dari hasil penghitungan daya menggunakan beban linear dan nonlinear yang menarik arus ke beban yang bervariasi.

Pengujian dengan beban linear ini menggunakan beban berupa resistor dengan nilai bervariasi, mulai dari $\mathrm{R}=48,4 \mathrm{Ohm}$ hingga $484 \mathrm{Ohm}$. Dari hasil percobaan, didapati hasil pengujian galat rata-rata daya aktif adalah $0,28 \%$ dan daya semu $0,33 \%$. Grafik galat pengukuran daya aktif dan daya semu dapat dilihat pada Gambar 11. 


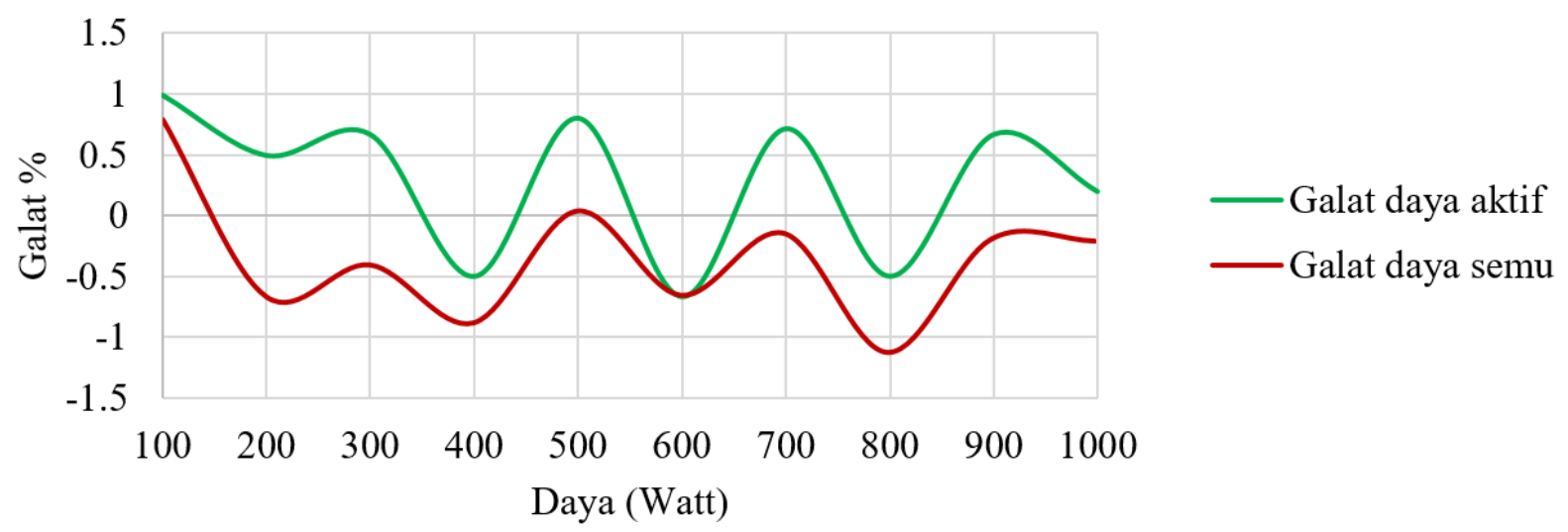

Gambar 11. Grafik galat pengukuran daya aktif dan daya semu untuk beban linear

Pengujian selanjutnya adalah untuk pengukuran faktor daya beban resistif. Pada pengujian beban dengan daya 100 hingga 300 watt, terukur nilai faktor daya 1 dengan galat $0 \%$. Semakin besar daya yang bekerja pada beban, maka galat perhitungan faktor daya juga semakin besar. Namun hingga beban 100 watt, nilai galat ini tidak melebihi $1 \%$. Pada beban ini, nilai faktor daya terhitung adalah sebesar 0,99 dari yang semestinya 1,00. Galat faktor daya dari hasil pengujian secara keseluruhan pada beban resistif dapat ditampilkan secara grafis pada Gambar 12.

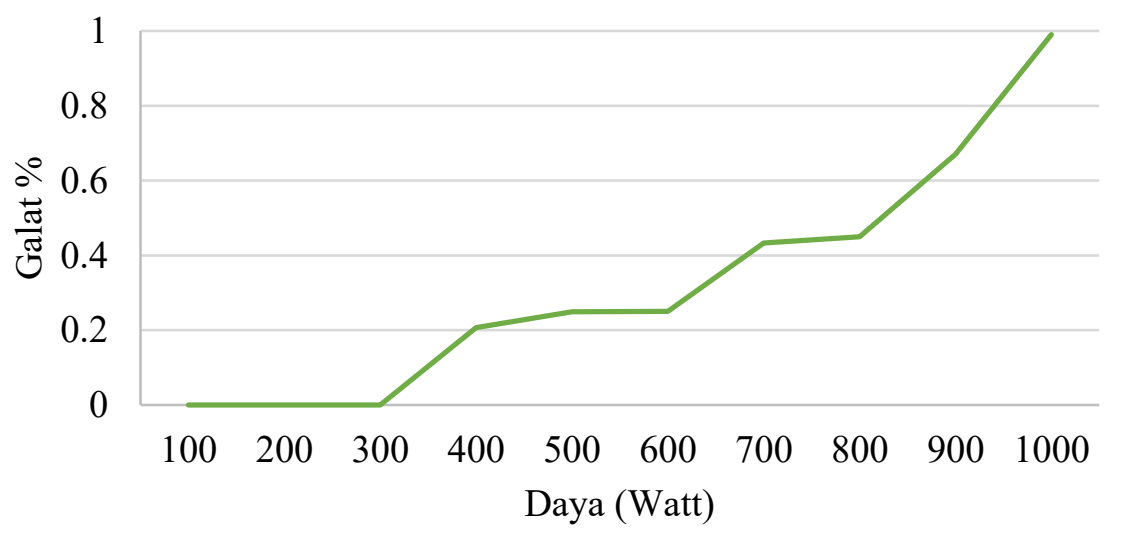

Gambar 12. Grafik galat pengukuran faktor daya

\subsection{Pengujian Beban Nonlinear}

Pengujian ini menggunakan beban berupa transformator dan diteruskan ke rangkaian penyearah gelombang. Beban nonlinear yang digunakan di sini sekaligus memiliki sifat faktor daya lagging. Grafik tegangan masukan dan arus beban dapat diambil dari memori mikrokontroler dan dapat ditampilkan secara grafis sebagaimana Gambar 13. Grafik tegangan berbentuk sinus murni namun grafik arus beban berbentuk sinus yang mengalami cacat. Hal ini disebabkan karena adanya rangkaian beban induktif dan komponen nonlinear yaitu dioda penyearah. Sementara itu, adanya sifat induktif transformator telah yang menyebabkan faktor daya bersifat lagging. 


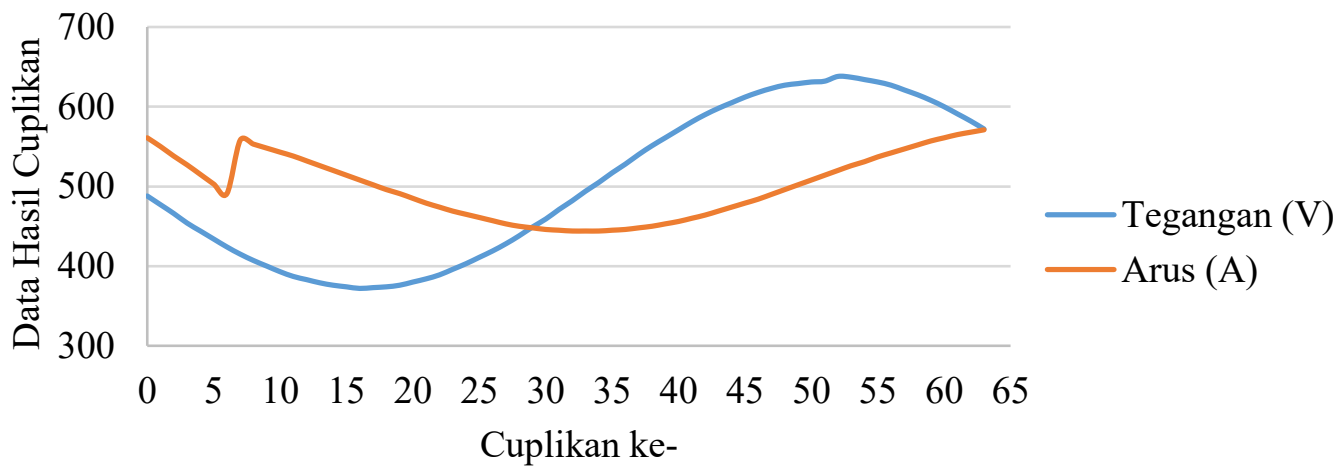

Gambar 13. Grafik hasil cuplikan tegangan dan arus beban nonlinear

Dari percobaan ini didapati galat rata-rata pengukuran daya aktif dan daya semu adalah $1,86 \%$ dan $0,47 \%$. Nilai galat hasil pengukuran pada beban nonlinear ini lebih besar daripada galat pada beban linear. Galat hasil pengukuran untuk berbagai nilai daya dapat dilihat pada Gambar 14.

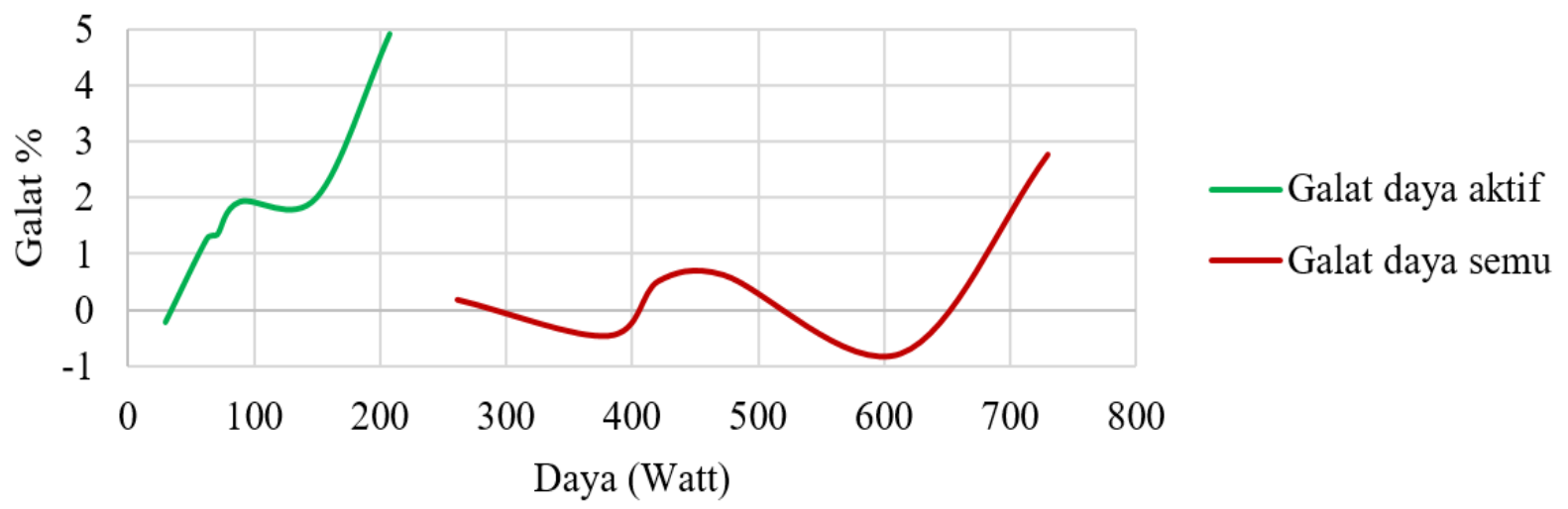

Gambar 14. Grafik galat daya aktif dan daya semu beban nonlinear

Berdasarkan pengujian daya aktif dan semu pada beban nonlinear yang telah diuji, didapati faktor daya yang terukur adalah 0,11 hingga 0,28 . Galat rata-rata pengukuran faktor daya adalah $0,21 \%$. Grafik galat faktor daya pada percobaan dengan beban nonlinear ini dapat dilihat pada Gambar 15.

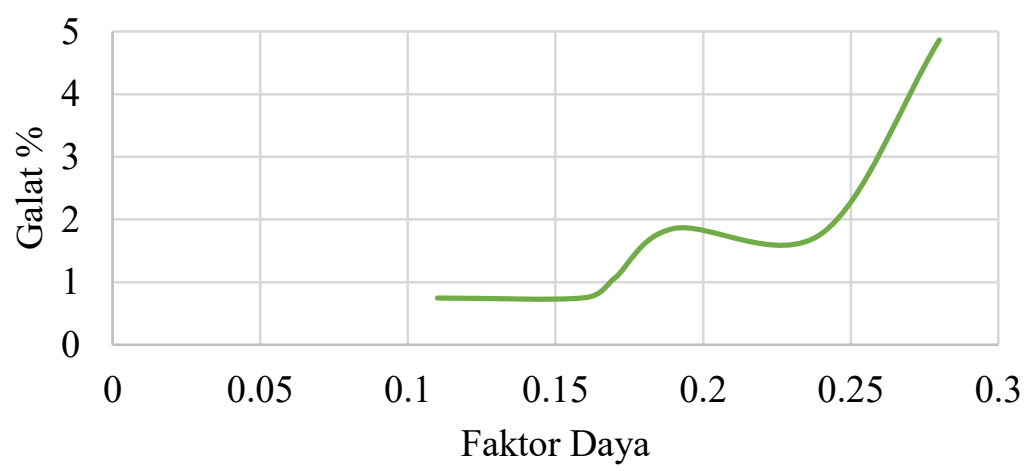

Gambar 15. Grafik galat faktor daya beban nonlinear 


\subsection{Pengembangan Sistem}

Sistem ini dapat mengukur nilai daya dan faktor daya untuk tegangan dan frekuensi tegangan yang bervariasi. Di mana tegangan dan frekuensi tegangan yang tidak stabil dapat terjadi pada keluaran generator skala kecil seperti generator pada pembangkit listrik mikrohidro [11-12]. Diharapkan sistem ini juga dapat dikembangkan untuk melakukan pengukuran sistem tegangan dan beban listrik 3 fase sehingga dapat digunakan untuk penelitian kinerja motor industri atas perubahan tegangan atau beban [13]. Dengan terekamnya grafik tegangan dan arus ke beban, sistem ini diharapkan juga dapat dikembangkan menjadi pemonitor grafik tegangan dan arus beban.

\section{Kesimpulan}

Mikrokontroler ATmega 328P dapat digunakan untuk mengukur daya dan faktor daya dengan cara mencuplik nilai isyarat tegangan dan arus secara bergantian dengan frekuensi cuplik 64 kali dari frekuensi tegangan masukan. Dari hasil perhitungan nilai tegangan dan arus RMS, maka dapat dilakukan penghitungan daya dan faktor daya. Sistem yang dibangun ini dapat digunakan sebagai pengukur daya dan faktor daya listrik dengan rentang tegangan 100 volt hingga 300 volt dengan rentang frekuensi masukan $45 \mathrm{~Hz}$ hingga $156 \mathrm{~Hz}$. Sistem ini juga dapat menentukan nilai daya semu, daya aktif, faktor daya di samping nilai true-RMS nilai tegangan dan arus. Rata-rata galat penghitungan daya aktif sebesar 0,28 \% dan untuk daya semu adalah $-0,33 \%$ pada beban linear yang memiliki sifat faktor daya unity. Sedangkan untuk beban nonlinear, rata-rata galat daya aktif sebesar $1,86 \%$ dan galat daya semu adalah $0,47 \%$ untuk faktor daya lagging.

\section{Daftar Pustaka}

[1] Kurniawan, F. (2012). Wattmeter Digital Berbasis Mikrokontroler. Jurnal Teknoin, Maret, 18(1), 13-25.

[2] Nanda, F. W., Kurniawan, F., \& Setiawan, P. (2020). Analisis Ketepatan Pengukur Tegangan True RMS Jala-Jala Listrik Berbasis Mikrokontroler ATmega 328P. AVITEC, 2(2), 111-128.

[3] Rustianik, Y., (2020). Analisis Ketepatan Pengukur Arus RMS Beban Listrik Berbasis Mikrokontroler ATmega 328P. Skripsi. Program Studi Teknik Elektro. Sekolah Tinggi Teknologi Adisutjipto: Yogyakarta.

[4] Fauziah, N., (2020). Analisis Ketepatan Pengukur Frekuensi Listrik Berbasis Mikrokontroler ATmega 328P. Skripsi. Program Studi Teknik Elektro. Sekolah Tinggi Teknologi Adisutjipto.

[5] Atmel. (2014). ATmega 640/V-1280/V-1281/V-2560/V-2561/V 8-bit Microcontroller with 16/32/64KB In-System Programmable Flash, Atmel Corporation, California, U.S.A.

[6] Belly, Alto, dkk. (2010). Daya Aktif, Reaktif, \& Nyata. Jurusan Teknik Elektro. Universitas Indonesia: Jakarta.

[7] Suprianto. (2015). Pengertian Daya Semu, Daya Nyata dan Daya Reaktif. http://blog.unnes.ac.id/antosupri/pengertian-daya-semu-daya-nyata-dan-daya-reaktif (diakses 3 Oktober 2020).

[8] Kurniawan, F. (2009). Implementasi Mikrokontroler sebagai Pencacah Frekuensi Berbasis Pengukuran Periode Isyarat Masukan. TELKOMNIKA, 7(1), 57.

[9] Kurniawan, F. (2011). Implementasi Pengukur Nilai Tegangan RMS Jala-jala Listrik berbasis Mikrokontroler. Jurnal Angkasa, 3(1), 177-189.

[10] Pelgrom, Marcel J.M. (2013). Analogue To Digital Converter. Springer Science \& Business Media: Netherlands.

[11] Prasetyo, J., \& Sunardi, S. (2019). Kincir Bertingkat pada Pembangkit Listrik Mikrohidro. AVITEC, 1(1), 71-76. 
[12] Ristianto, P., \& Sunardi, S. (2019). Generator Ganda pada Pembangkit Listrik Mikrohidro dengan Turbin Tunggal. AVITEC, 1(1), 65-70.

[13] Setiawan, P. (2019). Analisis Pengaruh Tegangan Tidak Seimbang pada Kinerja Motor Induksi Menggunakan Metode Transformasi Direct Quadrature. AVITEC, 1(1), 15-28. 